\title{
Cardiac amyloidosis: a case series review
}

\author{
Amiloidosis cardíaca: revisión de una serie de casos \\ Marina Povar-Echeverría1*, Pablo E. Auquilla-Clavijo², Bienvenido J. Povar-Marco³, \\ Eva M. Moreno-Esteban ${ }^{2}$, and María P. Figueras-Villalba ${ }^{1}$ \\ ${ }^{1}$ Department of Internal Medicine; ${ }^{2}$ Department of Cardiology; ${ }^{3}$ Emergency Department. Hospital Universitario Miguel Servet, Zaragoza, Spain
}

\begin{abstract}
Background: Cardiac amyloidosis is an entity that remains underdiagnosed, despite recent advances in its diagnosis and treatment. Objective: The aim of this study is to review a series of cardiac amyloidosis cases to describe the main clinical data and the findings in the imaging tests. Materials and methods: Retrospective study of patients with primary or secondary diagnosis of cardiac amyloidosis in discharge reports of patients hospitalized in our center from 2006 to 2016. The clinical data of the patients were reviewed, as well as the imaging tests (Electrocardiogram [ECG], echocardiogram, cardiac scintigraphy, and cardiac magnetic resonance). Patients were followed until January 2018. Results: We analyze 30 patients (20 men) with an average of 65 years. The main echocardiographic data were biatrial dilatation, diastolic dysfunction, and left ventricular hypertrophy (LVH) in $97 \%$. Only $6.7 \%$ met criteria for $L V H$ in the ECG. Up to $33 \%$ had systolic dysfunction. Scintigraphy and cardiac magnetic resonance were performed in 33\%. Survival at 12 months was $61 \%$. Conclusion: The presence of heart failure, atrial fibrillation, or conduction disorders with suggestive echocardiographic data should alert the clinician. Other data such as systolic dysfunction or female sex should not decrease the suspicion. The study should be completed with gammagraphy and cardiac magnetic resonance since early diagnosis has prognostic and therapeutic implications.
\end{abstract}

Key words: Amyloidosis. Transthyretin. Cardiomyopathy. Heart failure. ${ }^{99 m} T c-D P D$ scintigraphy.

\section{Resumen}

Antecedentes y objetivo: La amiloidosis cardíaca es una entidad que permanece infradiagnosticada, a pesar de los avances recientes en su diagnóstico y tratamiento. El objetivo de este estudio es revisar una serie de casos de amiloidosis cardíaca para describir los principales datos clínicos y los hallazgos en las pruebas de imagen. Materiales y métodos: Estudio retrospectivo de pacientes con diagnóstico principal o secundario de amiloidosis cardíaca en los informes de alta de pacientes hospitalizados en este centro desde 2006 hasta 2016. Se revisaron los datos clínicos de los pacientes, así como las pruebas de imagen (ECG, ecocardiograma, gammagrafía cardíaca, resonancia magnética cardíaca). Se realizó seguimiento de los pacientes hasta enero de 2018. Resultados: Se analiza a 30 pacientes (20 varones) con media de 65 años. Los principales datos ecocardiográficos fueron dilatación biauricular, disfunción diastólica e hipertrofia ventricular izquierda (HVI) en un $97 \%$. Sólo el $6.7 \%$ cumplía criterios de HVI en el electrocardiograma. Hasta un 33\% tenía disfunción sistólica. Se realizó gammagrafía y resonancia magnética cardíaca en un 33\%. La supervivencia a los 12 meses fue de 61\%. Conclusión: La presencia de insuficiencia cardíaca, fibrilación auricular o trastornos de conducción junto a datos ecocardiográficos indicativos

\section{Correspondence:}

*Marina Povar-Echeverría

E-mail: marinapovar89@gmail.com
Available online: 04-12-2020 2604-7063 / @ 2020 Instituto Nacional de Cardiología Ignacio Chávez. Published by Permanyer. This is an open access article under the CC BY-NC-ND license (http://creativecommons.org/licenses/by-nc-nd/4.0/).

Date of reception: 29-05-2019

Date of acceptance: 17-12-2019

DOI: 10.24875/ACME.M20000125
Arch Cardiol Mex (Eng). 2020;90(3):234-240
www.archivoscardiologia.com
an open access article under the CC BY-NC-ND

Arch Cardiol Mex (Eng). 2020;90(3):234-240
www.archivoscardiologia.com
an open access article under the CC BY-NC-ND 
debe alertar al clínico. Otros datos como disfunción sistólica o sexo femenino no deben disminuir la sospecha. El estudio debe completarse con gammagrafía y resonancia magnética cardíaca, ya que el diagnóstico temprano tiene implicaciones pronósticas y terapéuticas.

Palabras clave: Amiloidosis. Transtirretina. Miocardiopatía. Insuficiencia cardíaca. ${ }^{99 m} T c-D P D$ gammagrafía.

\section{Introduction}

Cardiac amyloidosis is the result of amyloid deposition in myocytes, which causes cardiomyopathy with restrictive pathophysiology. Although there are more than 30 known proteins that can produce amyloid deposition, only five do it significantly at the cardiac level: light chains, which cause primary amyloidosis (AL), transthyretin (TTR), apolipoprotein' A-1 (AApoA-1), fibrinogen, and serum component $A$, which gives rise to secondary amyloidosis (AA). At present, cardiac TTR amyloidosis (ATTR) is considered to likely be more prevalent than $A L^{1}$, usually regarded as the most common. There is a hereditary ATTR, with more than 100 described mutations, and an acquired ATTR known as a wild-type ATTR (wtATTR).

wtATTR is an entity predominantly described in males between the sixth and seventh decades of life. Its prevalence is not precisely known, but it is likely to be an underdiagnosed entity ${ }^{1}$. Studies performed in autopsies show that TTR deposition prevalence in people older than 80 years is as high as $25 \%^{2}$. In necropsies of patients with heart failure and preserved ejection fraction (HFpEF), moderate to severe deposition was shown in $5 \%^{3}$. Other studies conducted using non-invasive tests have determined that the prevalence of ATTR in patients with HFpEF and left ventricular hypertrophy $(\mathrm{LVH})$ could be $13 \% 4,5$. These data suggest that wtATTR could be one of the main causes of HFpEF.

In recent years, significant advances have been made in the diagnosis and treatment of ATTR. The diagnostic criteria published by Gillmore et al. ${ }^{6}$ allow establishing a non-invasive diagnosis of the disease and perhaps at earlier stages. In addition, the ATTR-ACT study has shown that tafamidis, a drug that stabilizes TTR by preventing dissociation of the tetramer and its deposition in tissues, decreases all-cause and cardiovascular-origin mortality, and delays functional capacity, and quality of life deterioration ${ }^{5}$. Therefore, carrying out this study is considered of interest with the purpose to describe the clinical characteristics and findings in diagnostic imaging tests of a cohort of patients with cardiac amyloidosis diagnosed at the authors' center.

\section{Materials and methods}

Descriptive, retrospective study of patients diagnosed with cardiac amyloidosis in a tertiary care hospital from January 1, 2006, to September 31, 2016. Discharge reports with primary or secondary amyloidosis diagnosis (ICD-9 code 277.3) were selected. Repeated episodes in a single patient, individuals diagnosed with amyloid angiopathy whose clinical presentation was exclusively neurological and patients with systemic amyloidosis without clinical or imaging evidence of cardiologic involvement were excluded from the study. The patient selection process is shown in figure 1.

Clinical documentation of each one of the patients was reviewed, and the following data were recorded: age, gender, personal history (cardiovascular risk factors, family history of amyloidosis, and previous admissions), clinical presentation (cardiac and extracardiac symptoms), diagnostic tests performed, and survival. The presence of low voltages on electrocardiogram (ECG) was identified by a QRS amplitude $<1 \mathrm{mV}$ in all precordial leads or $<0.5 \mathrm{mV}$ in those of the limbs. To define ventricular hypertrophy on ECG, the Sokolow criterion (sum of S-wave in V1 and R-wave in V5 or V6 $>3.5 \mathrm{mV}$ ) was used. The pseudoinfarction pattern was defined as ECG abnormalities simulating a myocardial infarction in the absence of it. Microvascular angina was considered with clinical signs and angor symptoms with a coronary angiography without significant lesions. A biopsy was conclusive if it demonstrated amyloid material deposition. Patient follow-up was extended until January 31, 2018, with a minimum period of 16 months, and was carried out by analyzing the available documentation in the electronic medical record and by telephone contact when it was necessary.

Statistical analysis was performed with the IBM SPSS Statistics 19 program. Quantitative variables were parametric using the Shapiro-Wilk test, and thus are presented as the mean and standard deviation; qualitative variables are presented as frequencies and percentages (\%). Survival was assessed using the Kaplan-Meier curve and the log-rank test. The Aragon Ethical Committee for Clinical Research authorized the study. 


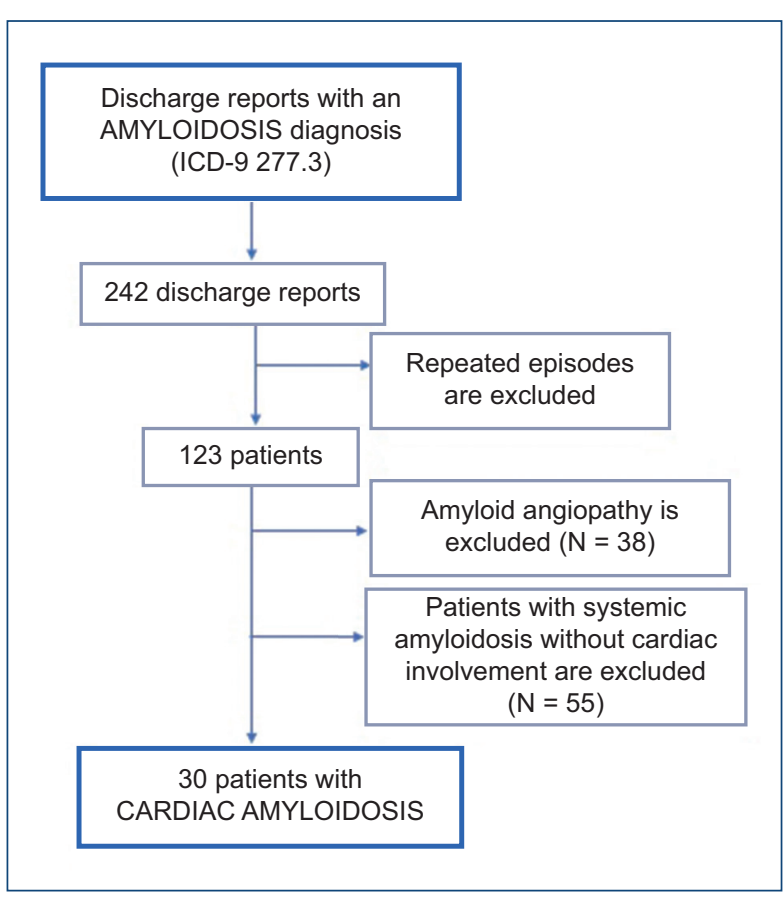

Figure 1. Algorithm showing the patient selection process.

\section{Results}

Thirty patients were included, 20 men and ten women, with a mean age of 65 years. The most common type of amyloidosis was primary ( $\mathrm{AL})$, present in ten patients (33\%); in five, it was hereditary (4 ATTR and 1 AApoA-1); in two, secondary (AA); and in two, wtATTR. In 11 subjects $(36.7 \%)$ the amyloidosis type was not identified.

At diagnosis, almost $60 \%$ of patients had previous admissions for heart failure, $20 \%$ were pacemaker carriers, and $10 \%$ had undergone carpal tunnel syndrome surgery. The predominant clinical presentation was heart failure $(90 \%)$, followed by conduction disorders that required pacemaker implantation (40\%); $43 \%$ of the patients had atrial fibrillation (AF), and $13 \%$, microvascular angina. Clinical presentation, cardiac and extracardiac symptoms are shown in table 1.

Regarding ECG findings, 50\% had some type of conduction disorder, and electrocardiographic patterns of low voltage and pseudoinfarction were also common; only $6.7 \%$ of patients met the criteria for LVH. Cardiomegaly was found in $93 \%$ of individuals on chest X-ray. On echocardiogram, $96 \%$ showed LVH, and $33 \%$ had depressed left ventricular ejection fraction (LVEF); $86 \%$ exhibited some degree of diastolic function alteration, most often Grade III (restrictive pattern). Only 26\% showed the granular or sparkling myocardial pattern. Some degree of the left atrial dilation was observed in $80 \%$, whereas $53 \%$ showed the right atrial dilation. Right ventricle dilation and dysfunction were reported in $30 \%$. As for valve disease, some degree of aortic stenosis was found in $20 \%$ of patients. The remaining echocardiographic parameters are detailed in table 1. Cardiac magnetic resonance imaging (MRI) was performed in ten patients, which was diagnostic in all cases: in seven subjects, late global sub-endocardial gadolinium enhancement was observed, and in three, distribution in patches. Only in four of the nine patients, cardiac scintigraphy showed myocardial uptake. In 27 individuals $(90 \%)$, anatomopathological study was carried out. The samples were taken by abdominal fat aspiration in six cases $(20 \%)$ or renal biopsy in six $(20 \%)$, rectal mucosa biopsy in three $(10 \%)$, endomyocardial biopsy in three (10\%), and salivary gland biopsy in one (3\%), among others. The study was conclusive only in 20 of them.

During a median follow-up of 16 months (95\% confidence interval $[\mathrm{Cl}], 16-72)$ since diagnosis, 21 patients died $(70 \%$ of total). Median survival was 21 months, with a mean age of 69 years at the time of death. Twelve-, 24-, and 36-months survival was 61.6\% (95\% $\mathrm{Cl}, 41-76), 46 \%(95 \% \mathrm{Cl}, 27-63)$, and $42 \%(95 \% \mathrm{Cl}, 24-$ 60 ), respectively (Fig. 2).

\section{Discussion}

This study describes a cohort of patients diagnosed with cardiac amyloidosis with similar characteristics to those found in previous studies, with a predominance of male gender and elderly patients, and with heart failure as the most common presentation form. The obtained data allow making some considerations about the diagnostic process of this disease, given the increasing accessibility of cardiac imaging diagnostic tests and the new criteria proposed for non-invasive diagnosis ${ }^{6}$.

Heart failure was the most common form of presentation in this series, followed by conduction disorders requiring pacemaker implantation, in this case, with higher percentages than those described in the previous studies, where only $7 \%$ of cases had this clinical presentation ${ }^{7}$. Although a considerable percentage of patients had a history of heart failure or pacemaker implantation, the disease had gone unnoticed, even in the presence of typical data such as carpal tunnel syndrome or extracardiac symptoms. The importance of maintaining a high suspicion index to establish a 
Table 1. Patient clinical and electrocardiographic characteristics and echocardiographic parameters

\begin{tabular}{|c|c|c|c|}
\hline Clinical presentation & Total $(n=30)$ & Complementary tests & Total $(n=30)$ \\
\hline \multicolumn{2}{|c|}{ Cardiovascular clinical presentation } & \multicolumn{2}{|c|}{ Transthoracic echocardiography } \\
\hline Heart failure & $28(93.3)$ & LV hypertrophy & $29(96.7)$ \\
\hline Angina & $7(23.3)$ & Interventricular septum thickness* & $16.8 \pm 3.3$ \\
\hline Coronary artery disease & $3(10)$ & Preserved LV systolic function & $20(66.7)$ \\
\hline Microvascular angina & $4(13,3)$ & LV systolic dysfunction & $10(33.3)$ \\
\hline Syncope & $8(26.7)$ & Mild & $6(20)$ \\
\hline Pacemaker implantation & $12(40)$ & Moderate & $4(13.3)$ \\
\hline Atrioventricular block & $7(23.3)$ & Severe & 0 \\
\hline Brady-tachy syndrome & $2(6.7)$ & LVEF* $^{*}$ & $54 \pm 12.6$ \\
\hline Both & $3(10)$ & Myocardial granular pattern & $8(26.7)$ \\
\hline Supraventricular arrhythmias & $13(43.3)$ & Diastolic dysfunction & $26(86.7)$ \\
\hline Ventricular arrhythmias & $6(20)$ & E/a decrease & $8(26.7)$ \\
\hline Pericarditis & $1(3.3)$ & Pseudonormal pattern & $4(13.3)$ \\
\hline Peripheral thromboembolism & $2(6.7)$ & Restrictive filling pattern & $14(46,7)$ \\
\hline \multicolumn{2}{|c|}{ Extracardiac symptoms } & LA dilation & $24(80)$ \\
\hline Neuropathy & $6(20)$ & RA dilation & $16(53.3)$ \\
\hline Hepatomegaly & $13(43.3)$ & RV dilation & $9(30)$ \\
\hline Anemia & $17(56.7)$ & RV disfunction & $9(30)$ \\
\hline Kidney failure & $16(53.3)$ & TAPSE* & $16.4 \pm 2.7$ \\
\hline Nephrotic syndrome & $9(30)$ & PASP* & $43 \pm 10$ \\
\hline Hematologic disease & $8(26.7)$ & Aortic stenosis & $6(20)$ \\
\hline Lymphoma & $1(3.3)$ & Light & $4(13.3)$ \\
\hline Multiple myeloma & $5(16.7)$ & Moderate & $2(6.7)$ \\
\hline MGUS & $2(6.7)$ & Aortic regurgitation & $7(23.3)$ \\
\hline \multicolumn{2}{|c|}{ Complementary tests } & Light & $4(13.3)$ \\
\hline \multicolumn{2}{|l|}{ Electrocardiogram } & Moderate & $3(10)$ \\
\hline Low voltages & $8(26.7)$ & Mitral regurgitation & $20(66.7)$ \\
\hline LV hypertrophy criteria & $2(6.7)$ & Mild & $14(46.7)$ \\
\hline Pseudoinfarction pattern & $8(26.7)$ & Moderate & $6(20)$ \\
\hline Conduction disorder & $15(50)$ & Intracardiac thrombus & $1(3.3)$ \\
\hline First degree AVB & $1(3,3)$ & Pericardial effusion & $10(33.3)$ \\
\hline Second degree AVB & $1(3,3)$ & Light & $5(16.7)$ \\
\hline Advanced AVB & $4(13,3)$ & Moderate & $1(3.3)$ \\
\hline Intraventricular disorder & $9(30)$ & Severe & $4(13.3)$ \\
\hline
\end{tabular}

* Mean and standard deviation.

LV: left ventricle; AVB: atrioventricular block; MGUS: monoclonal gammopathy of undetermined significance; LVEF: left ventricular ejection fraction; LA: left atrium; RA: right atrium; RV: right ventricle; PASP: pulmonary artery systolic pressure; TAPSE: Tricuspid annular plane systolic excursion. 


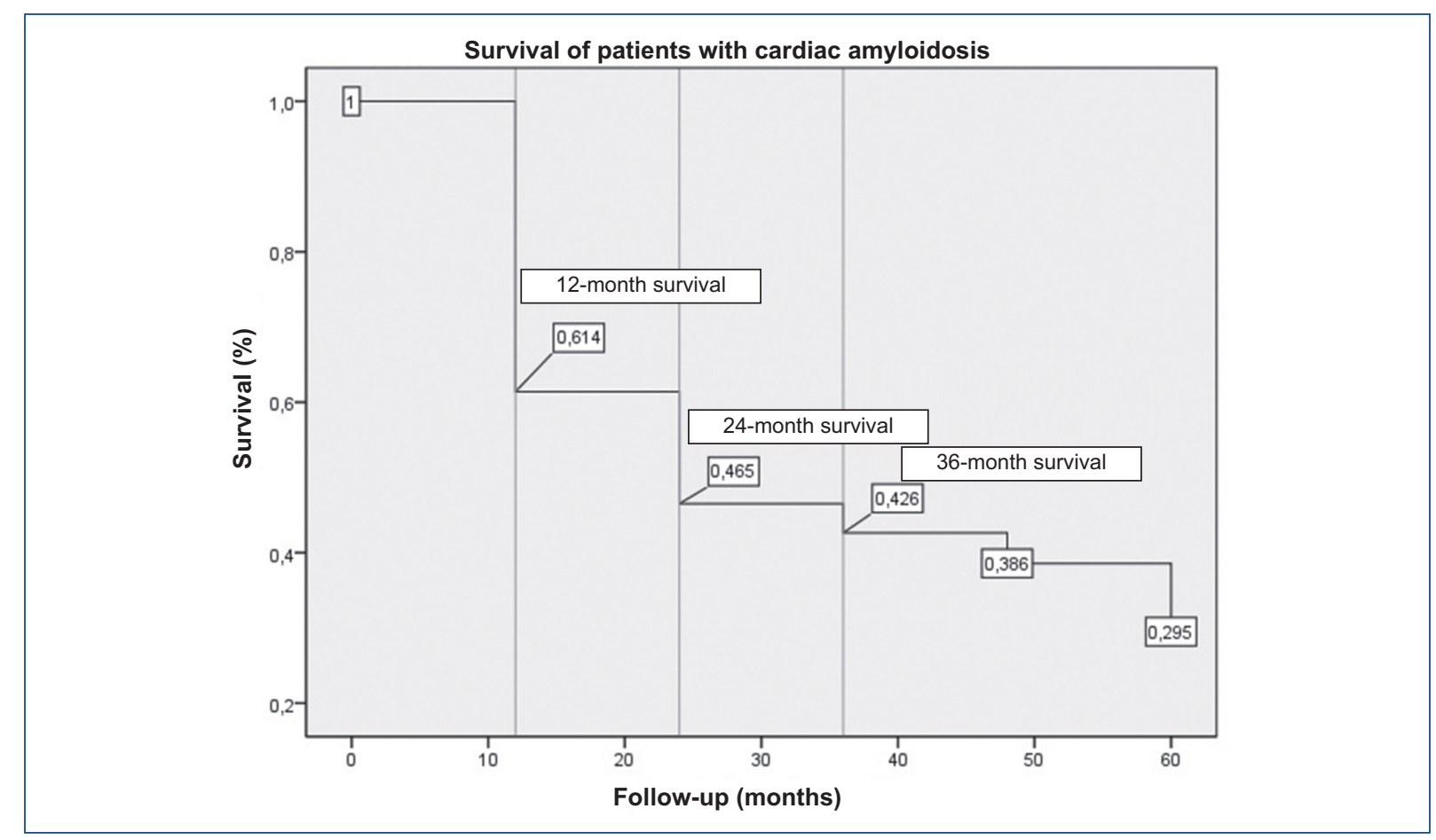

Figure 2. Overall survival of patients with cardiac amyloidosis.

diagnosis early is known ${ }^{8}$, which avoids missing diagnostic opportunities. In this sense, despite the usual male predominance in this disease, the female gender should not lower the suspicion threshold, since one-third of the patients were females, an even higher percentage than the $18-20 \%$ rates observed in other studies ${ }^{7}$.

Other data that should be taken into consideration are LVH in the absence of obvious causes, such as uncontrolled high blood pressure or valve diseases, or coexistence of low voltages on ECG, and LVH on echocardiogram ${ }^{1,7,9}$. In this series, $96 \%$ of cases had LVH versus $6.7 \%$ who met the criteria for LVH on ECG, as an expression of amyloid deposition rather than myocyte hypertrophy. The mean value for the interventricular septum in these patients was $16 \mathrm{~mm}$, which is higher than that described in previous series ${ }^{1}$, suggesting that probably most of them were at advanced stages of the disease.

Although most patients show HFpEF, amyloidosis suspicion should not be restricted to this group, given that contractile function worsens as amyloid deposition progresses, and there may be varying degrees of systolic dysfunction, as revealed by $33 \%$ of patients in this study ${ }^{1}$. These data confirm the findings of the previous studies, where patients with LVEF $<50 \%$ reach percentages ranging $37-50 \%, 1,10$. It should be noted that systolic function evaluation in amyloidosis using the standard technique (LVEF by Simpson's biplane method) has limitations, given that slightly depressed values already imply significant myocardial damage ${ }^{1}$. Some novel echocardiographic modalities such as speckle-tracking strain assessment provide systolic function more appropriate indices and allow myocardial involvement detection at earlier stages ${ }^{11}$. Left ventricle global longitudinal strain is often significantly reduced particularly in this entity at the expense of the basal and middle segments, with apical segments preserved values ("apical cherry" typical pattern) ${ }^{12}$. Longitudinal global strain reduced values have been independently related to poorer prognosis in the follow-up patients with cardiac amyloidosis ${ }^{13}$.

Another common echocardiographic finding in this series was biatrial dilation, especially of the left atrium, which corresponded to similar percentages of diastolic dysfunction. These are typical findings of this disease and are described at similar percentages in the previous works ${ }^{2}$. The myocardial granular pattern or myocardial sparkling, considered a typical finding, was only present in $26 \%$ of patients, and has also been found at low percentages in other series ${ }^{9}$. Therefore, cardiac amyloidosis diagnostic suspicion should not be supported by this 
data alone, but by the previously-described set of echocardiographic signs.

Ventricular filling progressive restriction with increased end-diastolic pressures and secondary left atrium dilation favors a high prevalence of $\mathrm{AF}$, which was observed in the previous series ${ }^{7}$ and that reaches $43 \%$ in this study. The Mayo Clinic group has suggested that wtATTR should be ruled out in the presence of non-valvular AF diagnosis in elderly subjects ${ }^{10}$. The $20 \%$ prevalence of aortic stenosis in this series also stands out, which is consistent with the findings of several recent studies that show the presence of wtATTR in up to $6.5 \%$ of patients undergoing aortic valve replacement ${ }^{14}$. In this study, a poorer postoperative prognosis was observed in this subgroup of patients ${ }^{14}$. These data lead to consider whether it would be necessary to rule out the presence of wtATTR in elderly individuals with severe aortic stenosis before proposing a therapeutic behavior.

This work is previous to the publication of the non-invasive criteria for ATTR diagnosis proposed in 2016 and thus scintigraphy and MRI were barely used, and biopsy was performed in practically all cases, with poor efficiency: in $33 \%$ of the cases it was inconclusive, and the reference technique, endomyocardial biopsy, was only carried out in three patients. Extracardiac biopsy diagnostic efficiency in amyloidosis with exclusive cardiac involvement is poorly understood ${ }^{1}$, but the sensitivity of abdominal fat aspiration has been described to be lower than $15 \%{ }^{15}$, and the fact that a negative biopsy of an unaffected organ does not rule out the diagnosis should not be forgotten. At present, non-invasive criteria ${ }^{6}$ allow wtATTR diagnosis with sensitivity and a positive predictive value of $100 \%$ without the need for histological confirmation. These criteria are heart failure with an imaging test (echocardiography or cardiac MRI) indicative

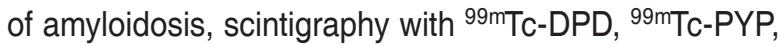
or ${ }^{99 \mathrm{mTC}} \mathrm{TMMDP}$ radiotracer cardiac uptake (Grades 2 or 3 ), and absence of detectable monoclonal protein by immunofixation in blood and urine $e^{6,16}$. It is probable that scintigraphy established wtATTR diagnosis in any of those patients in whom the biopsy was inconclusive, and thus it should be widely implemented in patients with clinical profiles consistent with this diagnosis.

Patient survival, including all types of amyloidosis, was $61 \%$ at 12 months, which is markedly lower than the $93 \%$ rate published by González-López ${ }^{7}$ in a series of wtATTR cases. wtATTR prognosis is better than that of other types, with a median survival of 75 months versus 13 for primary amyloidosis ${ }^{9}$. To determine wtATTR prognosis, a staging classification based on glomerular filtration rate and pro-BNP has been recently published $^{16}$.

The main limitation of this work is that it is based on a retrospective review of medical records, which implies a possible bias in information obtainment. The study describes the clinical characteristics of patients with cardiac amyloidosis in a single center and, consequently, the findings may not be generalizable and, in addition, the sample size is reduced. Given that this entity is probably underdiagnosed, this study has not taken into account the clinical characteristics and echocardiographic findings in this group of patients. Conducting a multicenter prospective study based on non-invasive diagnostic criteria to establish the true prevalence of wtATTR and its clinical characteristics would be of great interest.

\section{Conclusion}

The presence of heart failure, AF, conduction disorders and even aortic stenosis, together with echocardiographic signs such as ventricular hypertrophy, biatrial dilation, and advanced diastolic dysfunction, should alert about the presence of this entity. Other data, such as systolic dysfunction or female gender, should not attenuate clinical suspicion. Diagnostic workup should be completed with scintigraphy and cardiac MRI given that early diagnosis has prognostic and therapeutic implications.

\section{Funding}

The present research has not received specific aid from public or commercial sector agencies, or non-profit entities.

\section{Conflict of interests}

None.

\section{Ethical disclosures}

Protection of human and animal subjects. The authors declare that no experiments were performed on humans or animals for this research.

Confidentiality of data. The authors declare that they have followed the protocols of their work center on the publication of patient data.

Right to privacy and informed consent. The authors declare that no patient data appear in this article. 


\section{References}

1. González López E, López Sainz A, García Pavía P. Diagnóstico y tratamiento de la amiloidosis cardíaca por transtirretina. Progreso y esperanza. Rev Esp Cardiol. 2017;70(11):999-1004.

2. Maurer MS, Elliott $P$, Comenzo R, Semigran M, Rapezzi C. Addressing common questions encountered in the diagnosis and management of cardiac amyloidosis. Circulation 2017; 135:1357-1377.

3. Mohammed SF, Mirzoyev SA, Edwards WD, Dogan A, Grogan DR, Dunlay SM, et al. Left ventricular amyloid deposition in patients with heart failure and preserved ejection fraction. JACC Heart Fail. 2014;2(2): 113-122.

4. González-López E, Gallego-Delgado M, Guzzo-Merello G, de Haro-De Moral FJ, Cobo-Marcos M, Robles C, et al. Wild-type transthyretin amyloidosis as a cause of heart failure with preserved ejection fraction. Eur Heart J. 20157;36(38):2585-94

5. Maurer MS, Schwartz JH, Gundapaneni B, Elliott PM, Merlini G, Waddington-Cruz M, et al. ATTR-ACT Study Investigators. tafamidis treatment for patients with transthyretin amyloid cardiomyopathy. N Engl J Med. 2018:379(11):1007-1016.

6. Gillmore JD, Maurer MS, Falk RH, Merlini G, Damy T, Dispenzieri A et al. Nonbiopsy diagnosis of cardiac transthyretin amyloidosis. Circulation 2016;133(24):2404-12.

7. González-López E, Gagliardi C, Domínguez F, Quarta CC, de Haro-Del Moral FJ, Milandri A, et al. Clinical characteristics of wildtype transthyretin cardiac amyloidosis: disproving myths. Eur Heart J. 2017;38(24) 1895-1904.
8. Culotta V, Moon JC. Amiloidosis cardíaca por transtirretina: antes una enfermedad monogénica minoritaria, ¿ahora una vía común de insuficiencia cardíaca? Rev Esp Cardiol. 2016;69:888-889.

9. García-Pavía P, Tomé-Esteban MT, Rapezzi C. Amiloidosis. También una enfermedad del corazón. Rev Esp Cardiol. 2011;64:797-808.

10. Grogan M, Scott CG, Kyle RA, Zeldenrust SR, Gertz MA, Lin G, et al. Natural history of wild-type transthyretin cardiac amyloidosis and risk stratification using a novel staging system. J Am Coll Cardiol. 2016;68:1014-1020.

11. Gertz MA, Benson MD, Dyck PJ, Grogan M, Coelho T, Cruz M, et al. Diagnosis, prognosis, and therapy of transthyretin amyloidosis. J Am Coll Cardiol. 2015;66:2451-2466.

12. Tops LF, Delgado V, Marsan NA, Bax JJ. Myocardial strain to detect subtle left ventricular systolic dysfunction. Eur J Heart Fail. 2017;19(3):307-313.

13. Buss SJ, Emami M, Mereles D, Korosoglou G, Kristen AV, Voss A, et al. Longitudinal left ventricular function for prediction of survival in systemic light-chain amyloidosis: incremental value compared with clinical and biochemical markers. J Am Coll Cardiol. 2012;60(12):1067-76.

14. Treibel TA, Fontana M, Gilbertson JA, Castelletti S, White SK, Scully PR, et al. Occult transthyretin cardiac amyloid in severe calcific aortic stenosis: prevalence and prognosis in patients undergoing surgical aortic valve replacement. Circ Cardiovasc Imaging 2016;9(8). pii: e005066.

15. Quarta CC, González-López E, Gilbertson JA, Botcher N, Rowczenio D, Petrie A, et al. Diagnostic sensivity of abdominal fat aspiration in cardiac amyloidosis. EHJ 2017:38:1905-1908.

16. Gillmore JD, Damy T, Fontana M, Hutchinson M, Lachmann HJ, Martínez-Naharro A, et al. A new staging system for cardiac transthyretin amyloidosis. Eur Heart J 2017. doi: 10.1093/eurheartj/ehx589. 